\title{
A linguagem visual religiosa em obras de Samuel Wesley: uma breve introdução em sua escolha de artistas e alguns aspectos iconográficos
}

\author{
The religious visual language in works of Samuel \\ Wesley: a short introduction into his choice of artists \\ and some iconographic aspects
}

\section{El lenguaje visual religioso en obras de Samuel Wesley: una breve introducción a su elección de artistas y algunos aspectos iconográficos}

\section{Helmut Renders*}

\begin{abstract}
RESUMO
Das 18 obras de Samuel Wesley (1662-1735), destacam-se a sua Vida de Jesus (1693) e a sua História do Antigo e Novo Testamento pelas suas dimensões, pelo seu uso de mais de 500 gravuras de dois artistas famosos da época, William Faithorne (1616-1701) e John Sturt (1658-1730), e pelo fato que elas foram durante a sua vida diversas vezes reeditadas. O artigo apresenta e interpreta a opção pelos dois gravuristas e seis gravuras dos dois livros e decorre sobre o significado do esforço do autor de apresentar temas e textos religiosos sagrados por meio da iconografia. Conclui-se que as imagens encontradas representam narrativas visuais variadas, usando tanto técnicas da emblemática como do apelo aos afetos, promovendo o envolvimento intelectual emocional d[a] leitor[a].

Palavras-chave: Linguagens religiosas; arte religiosa; cultura visual anglicana; experiência religiosa.
\end{abstract}

\begin{abstract}
Of the 18 works of Samuel Wesley (1662-1735), his Life of Jesus (1693) and his History of the Old and New Testament stand out for their dimensions, for their use of more than 500 engravings by two famous artists of the William Faithorne (1616-1701) and John Sturt (1658-1730), and due to the fact that they were reissued several times during his life. The article presents and interprets Wesley's option for these engravers, and six pictures from the two books and discusses the meaning of the author's effort to present sacred religious themes and texts through the use of iconography. It is concluded that the images represent a variety of visual narratives, using techniques of emblems and the appeal to affection, promoting the intellectual and emotional involvement of the reader in different ways.

Keywords: religious languages; religious art; Anglican visual culture; religious experience.
\end{abstract}

\section{RESUMEN}

De las 18 obras de Samuel Wesley (1662-1735), su Vida de Jesús (1693) y su Historia del Antiguo y Nuevo Testamento destacan por sus dimensiones, por el uso de más de 500 
grabados de dos famosos artistas de William Faithorne (1616-1701) y John Sturt (1658-1730), y debido al hecho de que fueron reeditados varias veces durante su vida. El artículo presenta e interpreta la opción de Wesley por estos grabadores y seis imágenes de los dos libros y analiza el significado del esfuerzo del autor por presentar temas y textos religiosos sagrados mediante el uso de la iconografía. Se concluye que las imágenes representan una variedad de narrativas visuales, utilizando técnicas de emblemas y la apelación al afecto, promoviendo la implicación intelectual y emocional del lector de diferentes formas.

Palabras claves: lenguas religiosas; arte religioso; cultura visual anglicana; experiencia religiosa.

\section{Introdução}

Falar de uma cultura visual evangélica do protestantismo de missão no Brasil continua sendo para muitos, fora e dentro da academia, uma novidade. Nossa pesquisa procura ampliar e diferenciar esta percepção e, ao mesmo tempo, procura investigar as origens dessa cultura e das suas ramificações, introduzir referências teóricas e propor métodos para o estudo de imagens, ilustrações e cartazes dessa cultura visual evangélica brasileira, em sua maioria, religiöse Gebrauchskunst, ${ }^{1}$ ou seja, arte religiosa popular. O texto em seguida traz um exemplo do passado e demonstra como a cultura visual da Igreja Metodista no Brasil, além dos impulsos iniciais recebidos dos EUA, também dá continuidade a uma vertente inglesa, que não somente envolve o spiritus rector do metodismo inglês de John Wesley (1703-1791), como recentemente explicitamos (RENDERS, 2019, p. 103-24), mas, conta também com uma contribuição ampla do seu pai, o sacerdote anglicano Samuel Wesley (16621735). Com outras palavras, John Wesley tinha acesso à cultura visual religiosa pela própria casa, evidentemente apreciada pelo seu pai e especialmente apreciada por ele por duas obras extensas. Assim, junta-se este artigo a outros esforços, como por exemplo, a obra de Peter Forsaith (2018), e lembra da existência de uma cultura visual metodista deste as suas origens inglesas e, nesse caso, do seu respetivo contexto.

Samuel Wesley publicou durante a sua vida dezoito obras distintas. ${ }^{2}$ A maioria dos seus textos são ou obras de poesia (WESLEY, 16853; 1695; 1705; 1726; 1734), obras sobre poesia (WESLEY, 1700a), obras

\footnotetext{
Arte religioso utilitária.
}

2 Nós seguimos Watson, Willison e Pickles (1971, col. 487), sob consideração de Chamberlin (1991, p. 51) e Thorphy (2009, p. 161 e 162). Em nossa bibliografia, não alistamos as reedições na ordem alfabética, mas, mencionamo-las junto as suas primeiras edições.

3 Apesar de que Griffith (1815, p. 418) menciona o ano 1685, ele comenta que Samuel Wesley teria publicado o livro com 19 anos, o que seria em 1681. 
de poesias relacionadas com textos bíblicos, ou obras como Vida de Jesus (WESLEY, 1693 [2. ed.1697]; fac-símile: 2011]; ou de partes do Antigo e Novo Testamento (WESLEY, 1701 [2. ed. 1715; 3. ed. 1716; 4. ed. 1717a]; 1704b [2. ed. 1715; 3. ed. 1716]; 1704c [2. ed. 1715; 3. 1717b]). ${ }^{4}$ Além disso, encontram-se quatro obras relacionadas ao grupo religioso chamado os dissidentes (WESLEY, 1703; 1704a; 1707; 1730) e uma obra sobre o preparo do[a] participante para a Santa Ceia (WESLEY, 1700b [2. ed. 1716; fac-símile: 2018]). Duas obras tratam de assuntos de costumes (WESLEY, 1698; 1724), e uma obra da sociedade religiosa de Epworth (WESLEY, 1701[1702]). Considerando que nove das dezoito obras são textos com poesias, às quais ainda podemos somar quatro reedições, o foco das publicações de Samuel está em textos poéticos, especialmente, em diálogo com narrativas bíblicas que somam, contando as suas reedições, oito obras. ${ }^{5}$ Essas oito obras se dividem em uma Vida de Jesus (WESLEY, 1693) e três volumes de textos do Novo Testamento (WESLEY, 1701) e Antigo Testamento (WESLEY, 1704) e todas estas obras bíblico-poéticas apresentam, ao lado das poesias de Samuel Wesley, paralelamente, sessenta gravuras de William Faithorne ${ }^{6}$ (WESLEY, 1693) e quatrocentos e oitenta e cinco gravuras de John Sturt (WESLEY, 1701, 1704b e 1704c), somando um total de quinhentos e vinte cinco gravuras (publicadas, inclusive entre três e duas vezes durante do tempo da sua vida). Isso nos leva à primeira conclusão intermediária que das obras maiores reeditadas (n. 2, 6, 7, 11 e 15 segundo a numeração na bibliografia), 80\% tinham gravuras (com a

4 Em relação as datas de publicação seguimos Thorphy (2009, p. 161 e 162). Chamberlin (1991, p. 51) desconhece a edição de 1704 e Griffith (1815, p. 419) em um catálogo (S.N., 1884, p. 342 [item 2888]), não contemplam as edições de 1716 e 1717.

5 O que corresponde também ao lugar reservado para Samuel Wesley na obra Bibliografia anglo-poética de Griffith (1815). Até recentemente, a poesia de Samuel Wesley é assunto, porém, mais no sentido da expressão da decadência de um gênero literário, o "épico", como George Sherburne e Donald F. Bond (1967, p. 889) afirmaram: "De fato, os gêneros clássicos haviam visto seus melhores dias antes de 1700. Milton alcançou a grandeza no épico. [...] A influência miltônia levou a um número lamentável de épicos bíblicos sem distinção. A Vida de Nosso Senhor Abençoado (1693), de Samuel Wesley, o velho (1662-1735) e Pindaric Gideon de Aaron Hill (1749) podem servir como exemplos". Na época isso era, eventualmente, visto de forma diferente. Entre outros, elogiam a obra por poesias que se encontram no seu início, Nahum Tate (1652-1715), poeta laureado da Inglaterra a partir de 1692, e Peter Anthony Motteux (1663-1718), o pai do jornalismo inglês, tradutor e escritor de operas populares, a obra. Justamente Tate finaliza a sua poesia com palavras opostas às de Sherburne e Bond: "Aqui, com todo o Paraíso recuperado, eles se encontraram, e o nobre trabalho de Milton agora está completo".

6 Existem dois gravadores do mesmo nome, William Faithorne, o velho (1616-1701) e William Faithorne, o jovem (1656-1701). 
exceção do n. 6, O piedoso comunicante corretamente preparado $\left.(1700 \mathrm{~b})^{7}\right)$. Em seguida, estudaremos, então, dois aspectos da cultura visual destas duas obras em duas seções, ${ }^{8}$ focando nos artistas escolhidos por Samuel Wesley alguns tipos de narrativas visuais encontradas em imagens distintas.

\section{A obra A Vida de Nosso Abençoado Senhor e Salvador Jesus Cristo de 1693: comentários a respeito da escolha do gravurista William Faithorne, o mais velho, e dois exemplos da sua iconografia}

Em relação ao artista criador das 60 gravuras, um número anunciado já no título Vida de nosso abençoado Senhor e Salvador Jesus Cristo [...] com sessenta gravuras, ${ }^{9}$ de Samuel Wesley, não encontramos em toda a obra, inclusive nas próprias gravuras, qualquer indicação. Entretanto, na página da Biblioteca Britânica [British Library] o nome William Faithorne é acrescido depois da menção das sessenta gravuras. ${ }^{10}$ Dos dois gravuristas ingleses com o mesmo nome, sendo eles pai (1656- [1701]; cf. FAGAN, 1885-1890, p. 155-56) e filho (1616-1691; cf. FAGAN, 1885-1890, p. 156-57), o pai é considerado o artista superior. Apontam três razões para supor que seja ele o executor das gravuras encontradas: a data da publicação, a qualidade das gravuras (NAGLER, 1836, p. 233-34) e uma grande semelhança no desenho da face de Cristo com outras obras de sua autoria como a gravura A traição de Cristo criada de 1653. As sessenta gravuras pertencem a última fase da vida de William Faithorne, o velho. Na época, desde os meados

Uma cópia da primeira edição da obra pode ser encontrada em www.archive.org (cf. referências bibliográficas). O texto nos dá uma ideia da formação ampla do seu autor com citações em hebraico e grego, por exemplo, na p. 33, e cotações dos pais da igreja e de teólogos ingleses.

8 Seria também muito interessante estudar as narrativas poéticas e iconográficas juntas, já que elas juntas, cada uma por si, até podem ser entendidas como um tipo de emblema "incompleto" que contém a pictura e a subscriptio, mas, não a inscriptio. A importância das narrativas-leituras poéticas das narrativas bíblicas - e, ao mesmo tempo, da vida - na Igreja Metodista do Brasil durante o século 20 demonstram um número de publicações de poesias pela Imprensa Metodista (cf. (BARBOSA, 1972; DUARTE, 1969; NUNES,1971; GIÓIA JUNIOR, 1974; GONÇALVES, 1945 e s.a.; PINHEIRO, 1972 e [s.a.]; VIANA,1940).

9 Literalmente: placas de cobre (“copper plates").

10 WESLEY, Samuel. The Life of Our Blessed Lord \& Saviour Jesus Christ. An heroic poem ... Illustrated by necessary notes ... also a prefatory discourse concerning heroic poetry. With sixty copper-plates [by William Faithorne]. London: Charles Harper; Benj. Motte, 1693 [Negrito, pelo autor]. Esta informação é depois mantida em outros lugares como a PICRYL The World's Largest Public Domain Source, a nossa fonte das folhas individuais usadas neste artigo. 
do século 18, Faithorne tinha se tornado uma celebridade com a fama de ser o primeiro gravurista inglês capaz de produzir na mesma qualidade dos famosos gravuristas do continente, incluindo gravuristas franceses, holandeses e alemães, que, até então, tinham dividido o mercado inglês de gravuras de alta qualidade entre eles. Samuel Wesley escolheu, então, um artista no auge da sua fama, e o próprio William Faithorne, sua vez, aparentemente não se negou a trabalhar com Samuel Wesley. ${ }^{11} \mathrm{Da}$ sua iconografia da obra gostaríamos de destacar dois aspectos: a sua relação com o ambiente político europeu em geral e uma ênfase em uma linguagem mais carregada de paixões.

A obra de abre com duas referências ao Cristo, salvador do mundo (figuras 1 e 2). Ao lado esquerdo, vemos esse motivo clássico conhecido desde o século 14 , aliás, tanto na arte católica como na arte protestante. ${ }^{12}$ Essa primeira gravura é acompanhada por um título em latim, Salvator Mundi, ${ }^{13}$ uma moda humanista da época renascentista. A segunda gravura (figura 2) que também pertence ainda à abertura do livro, repete na parte superior central o motivo do salvador do mundo, flanqueado por dois anjos que seguram nas suas mãos ou uma cruz, ou uma coroa de espinhos. O título da obra é repetido de forma reduzida, com destaque para as palavras $A$ vida de Cristo e as "um poema heroico, em dez livros com sessenta gravuras". Enquanto o texto se refere à vida de Jesus, destaca a iconografia a sua obra como vivificadora e salvífica, relacionando sua morte (cruz e coroa de espinhos) com o seu reinado na glória (Salvador do mundo). O peso maior, entretanto, leva o motivo duplamente destacado do Salvator Mundi, um motivo oriundo da época da renascença que se tornou muito popular durante a primeira fase da colonização nos países envolvidos nesse processo. Assim, instala-se também uma ambiguidade entre uma ênfase soteriológica universal e o contexto de colonialização britânica que na época contava com as colônias de Virginia (1607), da Nova Inglaterra (1620), de Delaware e da Pensilvânia (ambos em 1681).

\footnotetext{
11 A publicação da obra chamou a atenção da rainha Mary II da Inglaterra (1662-1694) que ofereceu para Samuel Wesley a paróquia de Epworth.

12 Entre outras, são conhecidas versões de Robert Campin (1435); Jan van Eyck (1440), Hans Memling (entre 1475 e 1499), Leonardo da Vinci (1500), Albrecht Dürer (1505), Ticiano (1560), El Greco (1600), Gian Lorenzo Bernini (1679).

13 O texto manual na parte superior da gravura escrita à mão determina o herdeiro depois do falecimento do proprietário e contém a data 1775. Isso sugere que ainda 80 anos depois da sua criação ela tinha certo "valor", seja ele mais ideal ou material.
} 
Figura 1: Samuel Wesley. $A$ vida de Cristo: um poema heroico. [Salvador do Mundo]

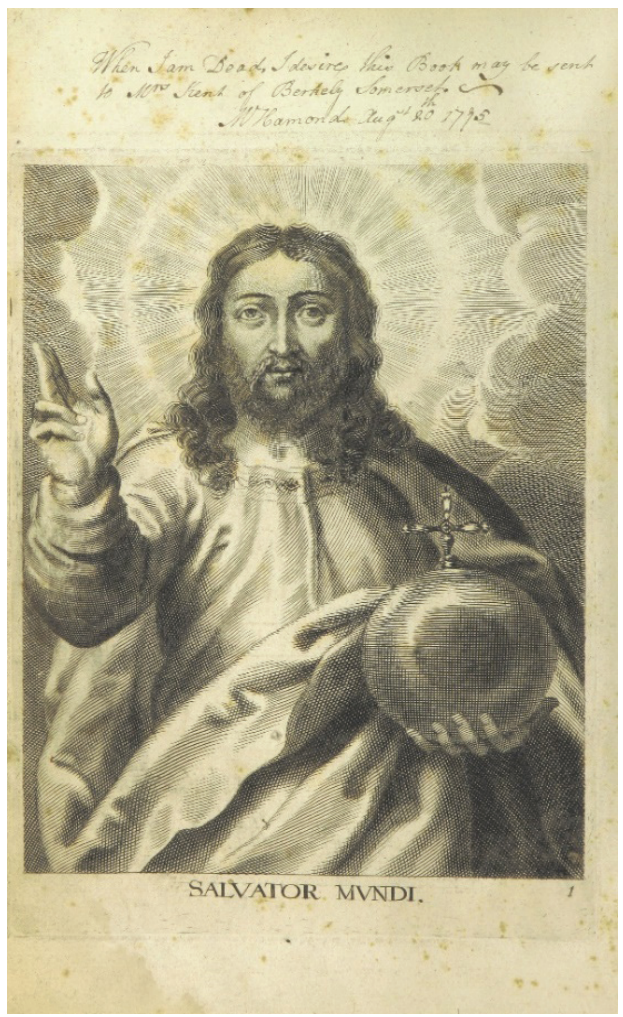

Fonte: British Library
Figura 2: Samuel Wesley. $A$ vida de Cristo: um poema heroico, 1693 [título]

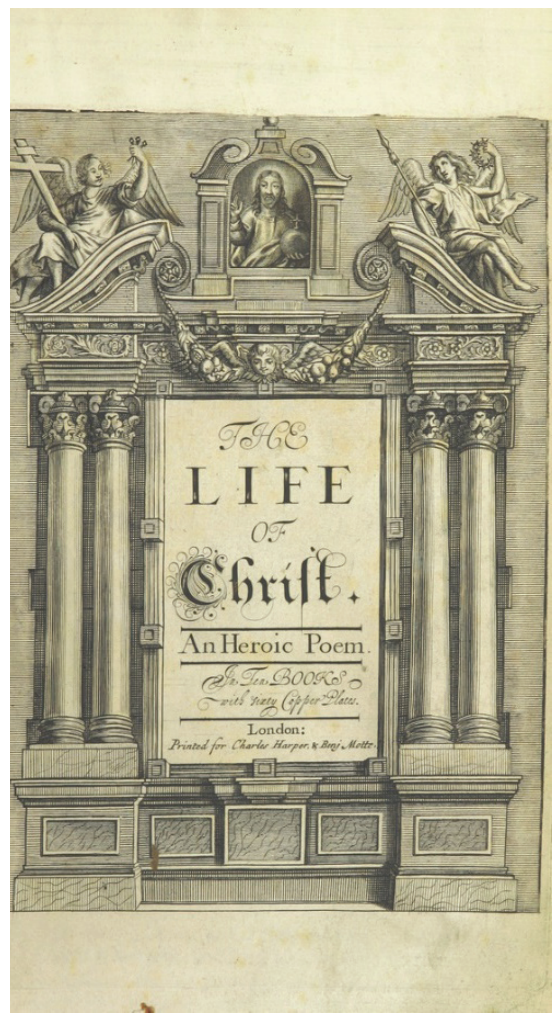

Fonte: British Library

Em seguida, estudamos duas gravuras que explicitam a dinâmica da linguagem visual usada por Faithorne: a cena da apresentação de Jesus (figuras 3 e 4) e a cena do assassinato das crianças recém-nascidas (figuras 5 e 6). Iniciamos com a linda cena da apresentação de Jesus.

A cena da apresentação segue uma composição clara que envolve nove pessoas e três animais. Ao lado esquerdo ficam José, Maria e o menino Jesus; ao redor do berço, um burro, uma vaca e uma ave morta (o que dá a ideia de um alimento trazido pelo grupo visitante). Ao lado direito, encontra-se um grupo de três mulheres e três homens, de idades diferentes. A cena é iluminada por uma luz que vem do lado esquerdo superior, ou seja, do lado direito de Deus em uma perspectiva teocêntrica e não antropocêntrica. ${ }^{14} \mathrm{~A}$ composição dos nove seres humanos dá a impressão de uma dupla dinâmica:

14 Característico para a arte católica. 
Há um "movimento" mais sutil do lado esquerdo para o lado direito da imagem, expressa pela luz e pelos gestos e olhares de José e Maria; há um avanço significativo do grupo das seis pessoas na direção à esquerda, expressa pelas posturas corporais, os gestos - com destaque na mão direita da mulher sentada na parte inferior centro-direita que penetra o lado esquerdo - e os olhares do grupo. Em conjunto, formam esse avanço e a expressa abertura e receptividade da santa família um conjunto que sinaliza uma harmonia que gera a expectativa que a aproximação gera proximidade.

Figura 3: Samuel Wesley. $A$ vida de Cristo: um poema heroico. [Lc 2.16]*

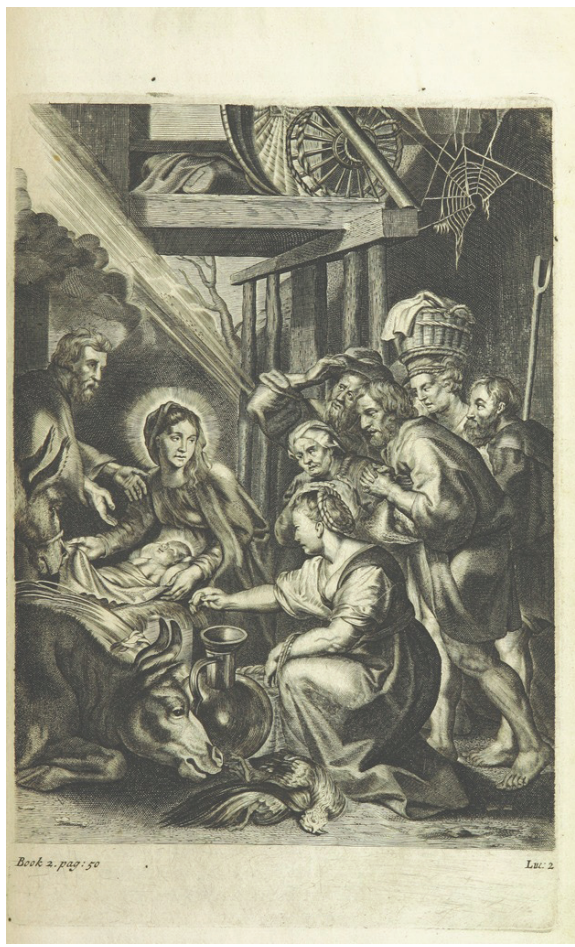

Fonte: British Library
Figura 4: Samuel Wesley. $A$ vida de Cristo: um poema heroico,1693

\section{[aspecto de composição]}

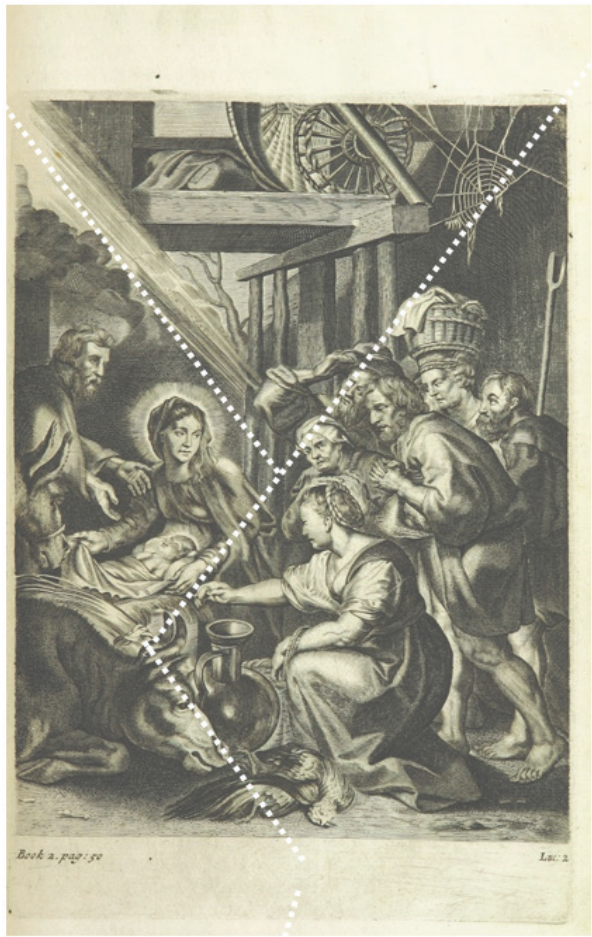

Fonte: British Library

O raio de luz e os olhares de todas as pessoas retratadas formam uma espiral: a luz chega ao grupo dos seis que olha para o menino Jesus, o menino Jesus olha para José e José e Maria olham para o grupo. Os gestos acompanham essa dinâmica visual. As mãos abertas de José, formam um

* Em Samuel Wesley, História do Novo Testamento, 1701. p. 147, o motivo também se encontra, como Luke II.16. Who come and worship him at the stable. 
gesto ou indicador - "vejam só" ou "isso aqui é para vocês"; as duas mãos da Maria seguram uma coberta, eventualmente, para retirá-la para que o grupo ao lado direito possa enxergar o milagre da sua vida; as duas mãos da figura masculina central ao lado direto são dobradas na atitude germânica de oração, mas seguram também um chapéu, recentemente tirado da sua cabeça (um movimento que a figura masculina atrás está começando a fazer). A luz ou o brilho, diferente do que em outras pinturas ou gravuras, não ilumina o berço ou a família sagrada, mas o grupo de mulheres e homens. Os movimentos dos dois lados à direção do lado oposto, a circularidade dos olhares e os gestos e expressões pelas mãos constroem uma cena que articula um movimento de aproximação, de carinho, de abertura mútua, enfim, de paz.

A outra imagem escolhida (figuras 5 e 6 ) articula paixões do outro lado da escala.

Figura 5: Samuel Wesley. A vida de Cristo: um poema heroico, 1701. p. 13 [Mt $11.16]^{* *}$

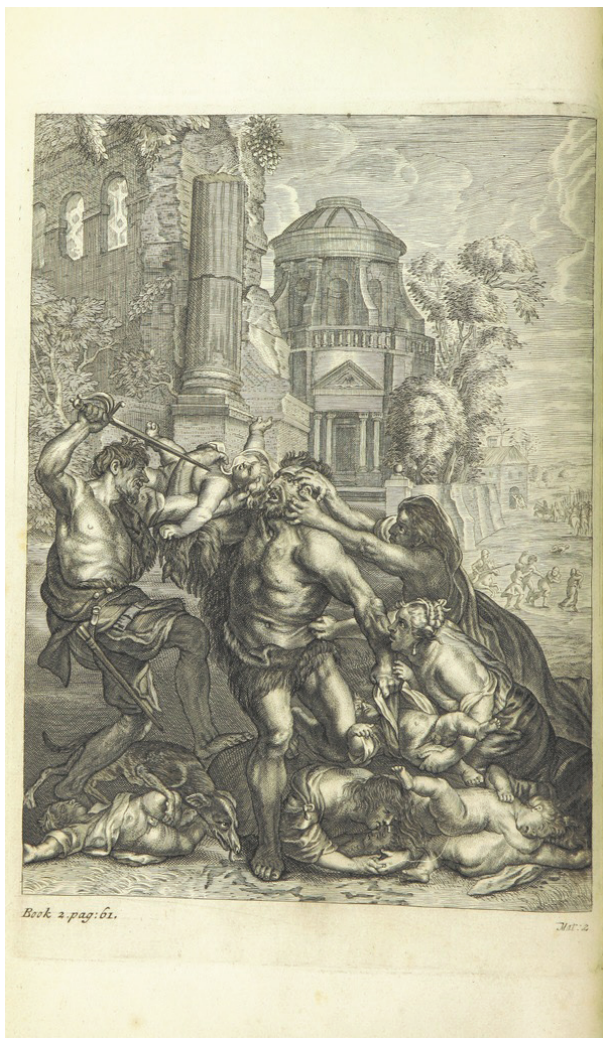

Fonte: British Library
Figura 6: Samuel Wesley, Samuel Wesley. A vida de Cristo: um poema heroico, 1701. p. 13 [aspectos de composição]

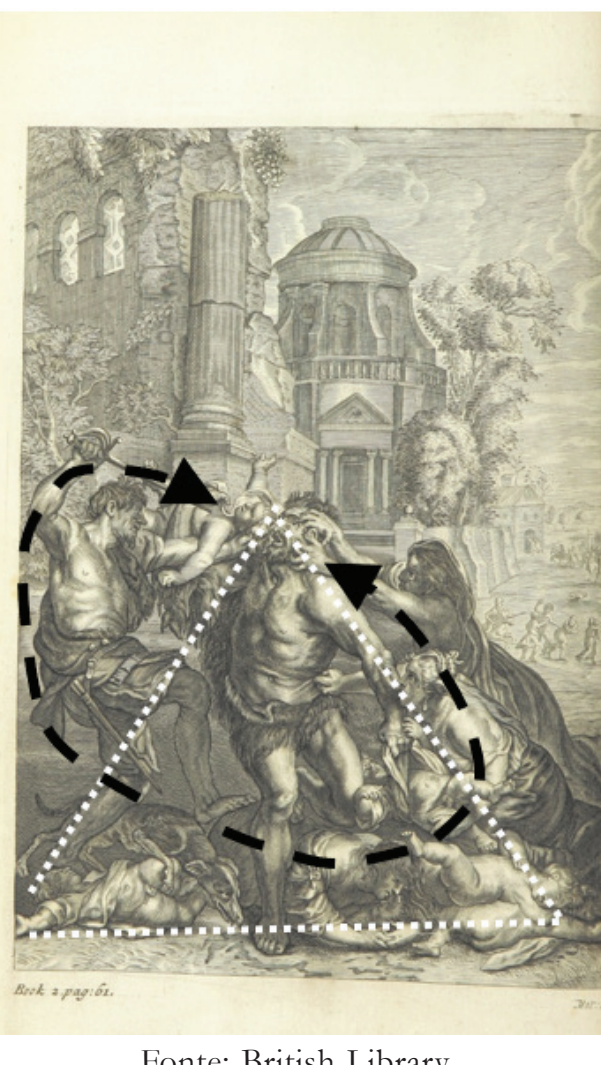

Fonte: British Library

** Em Samuel Wesley, História do Novo Testamento, 1701, p. 13, o motivo também se encontra como Matth.II.16. Herod's anger and the slaughter of the innocents. 
A cena comunica paixões fortes, de desafeto e violência, que partem das duas figuras masculinas. Uma delas segura uma espada na sua mão direita que aponta ao peito de uma criança segurada pela sua mão esquerda; a outra também segura uma criança, só que com a sua mão esquerda, e parece proteger o assassino contra os avanços de duas mulheres que procuram impedi-lo. A mulher em pé tenta chegar à criança ameaçada e segura a cabeça da figura central com as suas duas mãos que parecem ser garras, tanto que ela se esforça; a mulher sentada tenta ajudá-la e, ao mesmo tempo, libertar a criança da mão esquerda da figura central. Junto com mais duas crianças na parte inferior esquerda e direita, as quatro crianças da cena formam um triângulo. Assim, existem duas dinâmicas circulares. Primeiro, das duas crianças mortas se via a criança disputada, até a criança na beira da morte; segundo, da mulher deitada para a mulher sentada, até a mulher em pé. Assim, cria-se uma dinâmica de oposição entre as três mulheres e os dois homens, tudo ao redor das quatro crianças. Um retrato da violência de um sistema político que deixa cair a sua máscara, se é que ela existia antes. Anota-se a ausência de homens que lutam junto às mulheres pela vida. Por um lado, isso reforça a ideia do que será o resultado neste enfrentamento desigual; por outro lado, pergunta-se em que situação de uma sociedade cabe a mulheres sozinhas a defesa das suas crianças contra-ataques violentos. São mães solteiras? São famílias, cujos homens estão na guerra? De qualquer forma, trata-se de uma situação já desordenada ou desequilibrada. O mesmo vale para o retrato dos homens. O assassinato, não das mulheres - que aliás, ainda estão todas vivas -, mas, de crianças pequenas sem distinção, em todas as culturas é considerado um crime fortemente condenável. Assim, as duas gravuras articularam fortes ou significantes paixões: paz e pânico; esperança e desespero, proximidade e separação, encontro e desencontro, famílias intatas e famílias destruídas; um recém-nascido como símbolo de renovação da vida e a morte de recém-nascidos como símbolo absurdo de interrupção vida.

Um dos assassinos segura um épée o rapier, ou seja, uma arma do século 17, não da época de Jesus. Fora dessa atualização de vestimentas e instrumentos da época, nota-se um elemento, digamos, popular. Em outras épocas, teríamos encontrados numa cena da natividade e referências a governantes ou aos[às] patrocinadores[as] da obra, retratadas como adoradores[as] de Jesus. Nesse caso, indicam as roupas e as referências a profissões simples - uma das mulheres parece carregar roupa na sua cabeça, 
ou por ter lavado a mesma ou por querer vendê-la - um foco na população comum ou mais popular: é o povo que vem para adorara, mulheres e homens de forma igual. Enquanto a inclusão de pessoas simples se sintoniza com a referência aos pastores no evangelho de Lucas, representa a inclusão igualitária de mulheres um acento originário da gravura. $\mathrm{O}$ aspecto físico dos dois homens cena do assassinato das crianças representa da linguagem visual barroca criada para articular fortes paixões. Religião, assim a mensagem, deve provar a sua importância nas ambiguidades da vida. A paz de uma cena deve saber lidar com a violência da outra. O[A] leitor[a] e seu mundo são retratados e em meio dos desafios todos encontra-se uma promessa divina. As gravuras funcionam como um espelho. Eles revelam a capacidade humana de fazer o pior e a resistência contra isso, elas demonstram a capacidade de optar para um outro caminho, enquanto a oportunidade para isso se oferece. No meio desse conflito as gravuras colocam personagens do meio do povo, não das elites.

Não sabemos se Samuel Wesley falou com o artista sobre tudo isso, se ele tinha uma influência na escolha dos motivos, na sua elaboração e determinação das suas narrativas. Somente sabemos que acolhe o material usado. Pela escolha de um artista já com fama, sugere-se que ele considere as narrativas visuais importantes, eventualmente, em especial para leitores[as] menos letrados[as]. De qualquer forma, não se trata de ilustrações quaisquer, pelo contrário, trata-se de narrativas adicionais ao texto (e assuas poesias) com seu próprio peso e importância. ${ }^{15}$

\section{Os três volumes da História do Antigo e Novo Testamento, 1701 - 1704: comentários a respeito da escolha do gravurista John Sturt W, o mais velho, e dois exemplos da sua iconografia}

A segunda obra em questão reúne em três volumes de dois terços a três quartos dos textos do Antigo e do Novo Testamento. Sempre se juntam, uma passagem bíblica segundo a tradução King James da época, uma poesia de Samuel Wesley e uma gravura de John Sturt (1658-1730).

\footnotetext{
15 Com esse recorte nós não tratamos de um grupo de imagens recorrente nessa obra, os retratos de autores de textos bíblicos ou de figuras bíblicas que representam um terço de todas gravuras. Eles são menores, mas, se distinguem principalmente das outras imagens pela sua linguagem meramente alegórica, apresentando atributos da clássica hagiografia das personagens retratadas. Essa linguagem requer conhecimento cultural, foi desenvolvida na épica medieval e é pré-renacentista.
} 
Figura 7: Samuel Wesley. A bistória do Antigo e do Novo Testamento, 1716.

[Gravura de abertura da 2. edição]
Figura 8: Samuel Wesley. A bistória do Antigo e do Novo Testamento, 1716.

[Título da 2. edição]

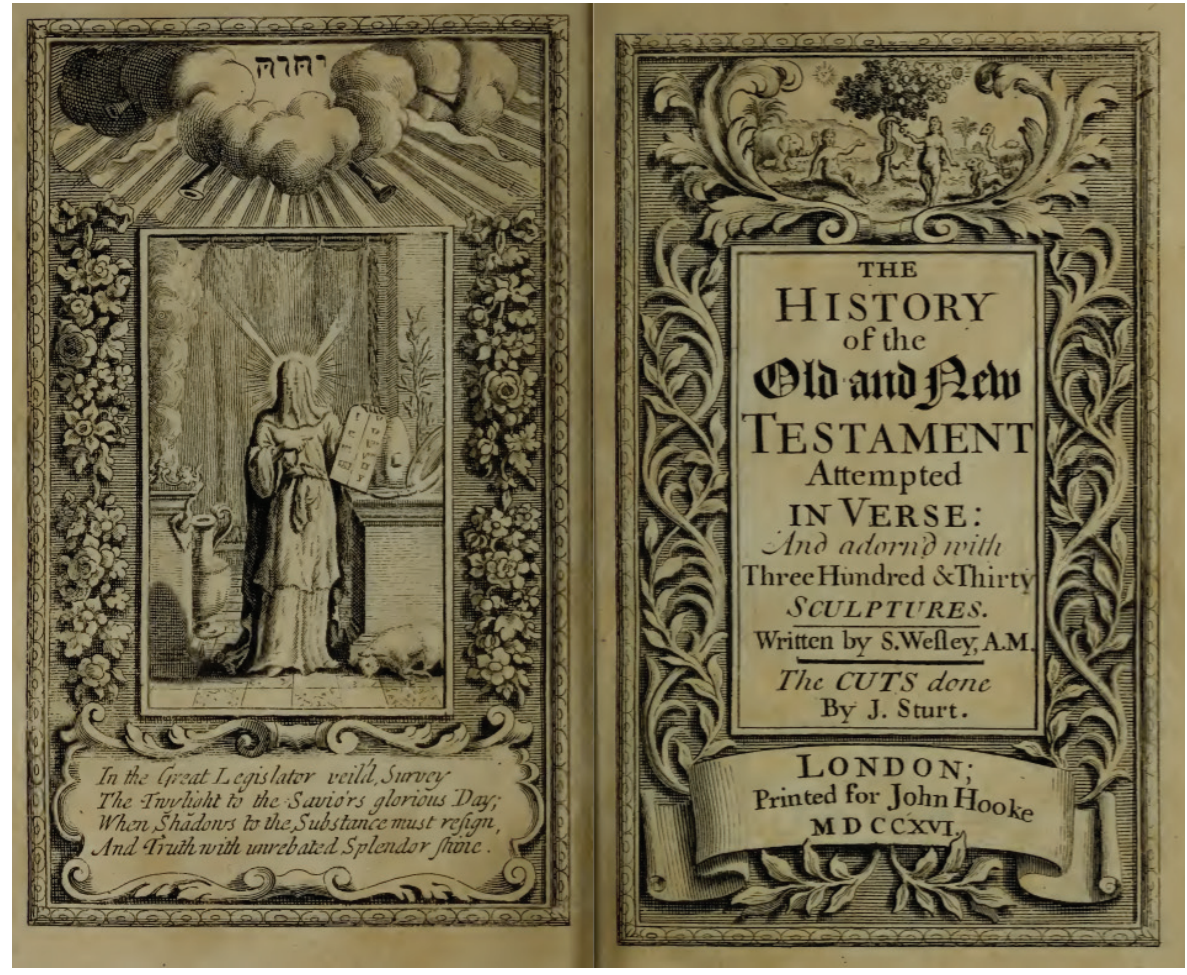

Fonte: Archive.org

Fonte: Archive.org

O primeiro volume lançado em 1701 reúne somente textos do Novo Testamento, os outros dois, inicialmente lançados em 1704, do Antigo Testamento. Na sua reedição em 1716 em três volumes mudou o título da então edição como coletânea completa para História do Antigo e do Novo Testamento (Cf. S.N., 1971, cl. 487). Desde então, a obra em três volumes nunca se perdeu de vista por completo no mundo anglo-saxão. Ela continuou sendo referenciada durante o século 18 em livros sobre a poesia inglesa (GRIFFITH, 1815, p. 419), ou em inventários de venda de bibliotecas particulares (S.N., 1834). Assim também não falta em uma mais recente publicação sobre edições históricas de Bíblias inglesas (CHAMBERLIN, 1991, p. 51) e continua sendo consultada em estudos específicos como A piedade preveniente de Samuel Wesley, sr. (TORPY, 2006 [tese]; 2009). Entretanto, precisa ser feita a ressalva que, mesmo que se menciona a obra, não se explora o seu aspecto imagético. Para finalizar, a editora Forgotten Books reeditou em 2019 os primeiros dois volumes do conjunto como fac-símile "on demand". 
Figura 9: Francis Bragge. A paixão do nosso Senhor, 1694, p. 178

[A multiplicação dos pães].

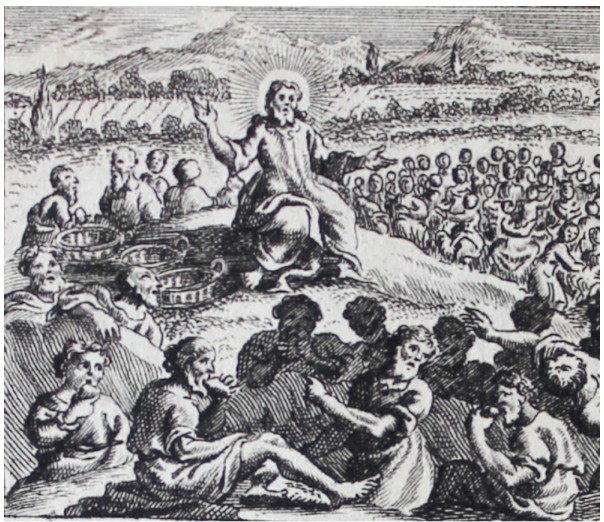

Fonte: www.archive.org
Figura 10: Samuel Wesley. $A$ bistória do Novo Testamento, 1701. Detalhe: A multiplicação dos pães; gravura de John Sturt.

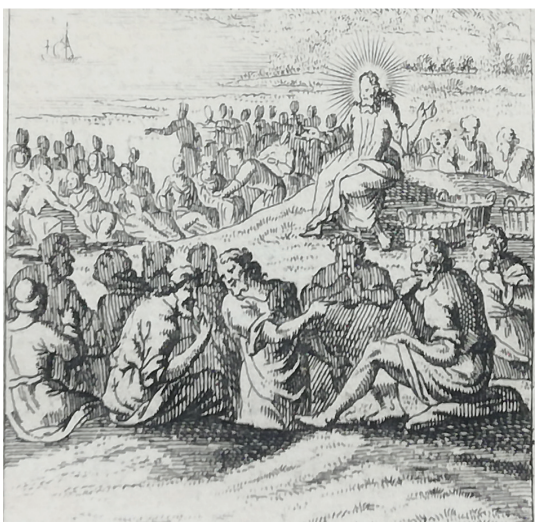

Fonte: www.archive.org

Em relação ao gravurista, podemos inicialmente repetir o que já observamos em relação a William Faithorne: John Sturt era um mestre da sua arte. Apesar de que o público mais amplo conhece ele até hoje como o primeiro ilustrador do livro O peregrino, de John Bunyan (1728), a sua obra mais sofisticada e superior era por certo a sua edição do Livro da Oração Comum da Igreja Anglicana (STURT, 1731), que conta não somente com gravuras da maior qualidade, mas, também com todo texto executado em caligrafia. E para completar a abrangência confessional das suas atividades, devemos ainda mencionar a sua ilustração da tradução inglesa da Pia desideria, de Hugo Herman ${ }^{16}$ que, em 1702, já estava na sua terceira edição. As obras de Bunyan e Herman são hoje consideradas clássicos do gênero dos guias devocionais, entretanto, de vertentes adversos: Herman desenvolve uma mística católica segunda o modelo da via tripla que relaciona a via purgativa, a via iluminativa e a via unitiva; Bunyan projetou no seu livro cheio de alegorias uma mística inspirada no modelo da tabula cebetis como peregrinação da cidade da destruição à cidade celestial. John Sturt, aparentemente, transitou bem entre católicos, anglicanos - aos quais pertencia Samuel Wesley - e puritanos. De fato, quando Samuel Wesley publicou em 1701 o primeiro volume, de sua História do Novo Testamento, Sturt somente tinha feito até então as gravuras para a Pia desideria de Hugo Herman e A paixão do nosso Senhor, de

16 O’Donoghue (1900, p. 138-39), menciona as suas gravuras na obra de Samuel Wesley, mas não de Hugo Hofman. 
Francis Bragge (1694). As gravuras da obra de Bragge e de Wesley, de fato, são parecidas, como a cena da multiplicação dos pães nas duas publicações evidencia (figuras 9 e 10): composição, a representação de figuras isoladas ou de grupos de pessoas, gestos, detalhes das cestas indicam a mesma autoria.

Figura 11: Samuel Wesley. A história do Antigo Testamento, 1704
Figura 12: Samuel Wesley. A bistória do Novo Testamento, 1701. p. 31 [Mt 7.13: Os caminhos estreito e largo $\left.{ }^{* * *}\right]$

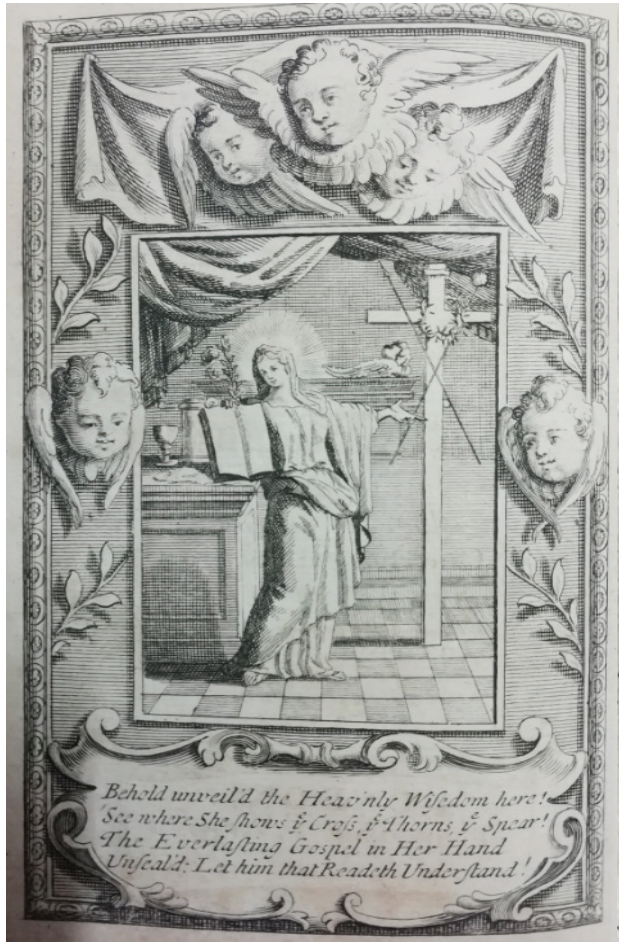

Fonte: www.archive.org

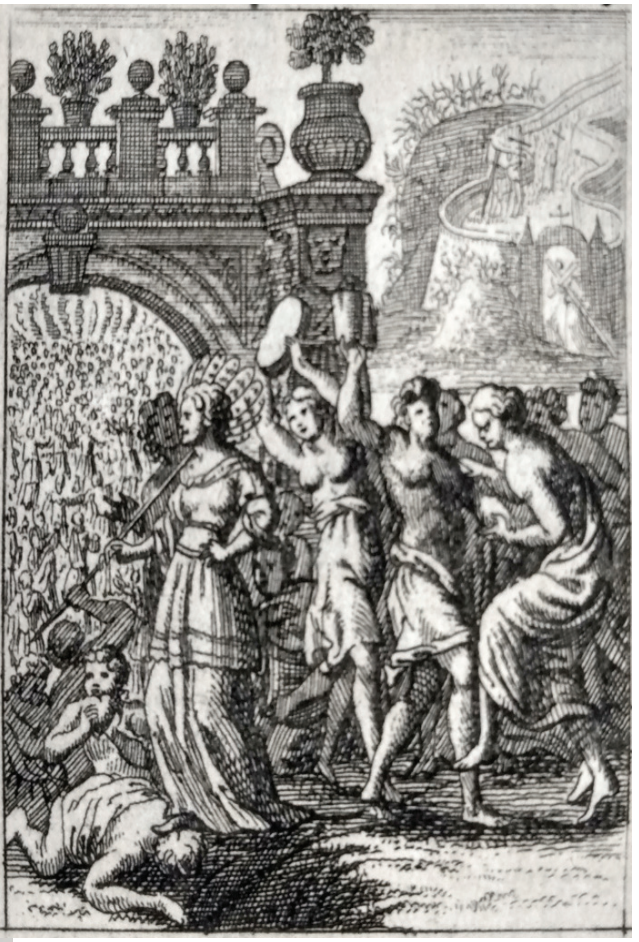

Fonte: www.archive.org

Mais, uma vez, escolha Samuel Wesley um especialista, o que certamente não foi barato. ${ }^{17}$ Aparente, considerando tanto a qualidade como a quantidade das imagens usadas nessa obra - mais do que 400 - Samuel Wesley entendia que as imagens tinham um papel importante na obra. Com outras palavras, Samuel Wesley empregou a cultura visual repetidamente, inclusive, nessa segunda obra em escala até maior, para comunicar o evangelho.

***Matth. VII.13. The narrow and the broad way.

$17 \mathrm{O}$ aspecto financeiro desses empreendimentos não se comenta na literatura. Fato é que Samuel Wesley foi em 1705 para pressão por não poder pagar as suas dívidas. Os investimentos nessas edições e suas repetidas impressões podem ter feitas parte do problema. 
Voltamo-nos agora a duas dessas tantas imagens. Iniciamos, novamente, com a capa (figura 11). Essa vez, o artista se utiliza de uma outra narrativa clássica, a narrativa dos emblemas, um gênero criado pelo italiano Andrea Alciato na França, porém publicado em 1531 em Augsburgo na Alemanha. 170 anos depois, a linguagem criada por humanistas para seus pares, igualmente apreciada pela aristocracia europeia, já tinha sido popularizada por todas as confissões como uma linguagem religiosa. A capa, então, é composta por dois elementos típicos de um emblema, a pictura e o subscriptio. A falta do terceiro elemento, o inscriptio ou o título, não incomum. No centro dessa pictura encontra-se uma figura feminina. A subscriptio identifica-a - nesse caso, na língua inglesa ${ }^{18}$ - como a representação da sabedoria de Deus: "Eis aqui a sabedoria celestial! / Veja como ela mostra a cruz, os espinhos, a lança. / O evangelho eterno em sua mão / não selado: quem lê entende!" Ao lado esquerdo da figura encontra-se um altar estilizado com um cálice ao seu topo e, no fundo, uma mesa comum com um coração com asas. Todo esse conjunto requer, na melhor tradição emblemática, envolver o[a] leitor[a] em um processo de interpretação que demanda conhecimento cultural e religioso. Nesse caso específico, por exemplo, precisa saber que motivo do coração com asas remete ao Salmo $55.6^{19}$ e se tornou no cristianismo um símbolo da experiência mística no contexto da busca de salvação. Estabelece-se, então, uma relação entre a palavra - chamado "o evangelho que dura para sempre" a eucaristia, a paixão de Jesus e a experiência religiosa. Interessante é também a relação assim estabelecida pelo gesto entre "a cruz, os espinhos, a lança" e o "evangelho que dura eternamente", ou seja, repete-se também nesta gravura de capa a pronúncia do aspecto salvífico. Em tudo, a iconografia da capa aponta para uma linguagem religiosa clássica que combina elementos simbólicos herdados do catolicismo medieval com aspectos do protestantismo e do humanismo. De qualquer forma, também indica que a leitura dessa palavra requer e envolvimento pessoal dos eu leitor e da sua leitura.

A próxima gravura (figura 12), é uma de dezenas de variações originárias do motivo dos dois caminhos, criadas nos séculos 16 a 19. Nesse caso específico, lembra do caminho largo somente um portal imenso e aberto. Em frente dele encontram-se três figuras femininas dançando, duas delas segurando instrumentos musicais. A cena lembra de longe o motivo das três ninfas dançando na obra Primavera de Sandro Botticelli (1482) e representa,

18 Behold unveil'd the heavenly wisdom here! / See where she shows ey cross, ey thorns, ey spear. / The everlasting gospel in her hand / Unsealed: let him that readeth understand!"

19 Salmo 55.4-6: “O meu coração está dolorido dentro de mim, e terrores da morte caíram sobre mim. Temor e tremor vieram sobre mim; e o horror me cobriu. Assim eu disse: Oh! quem me dera asas como de pomba! Então voaria, e estaria em descanso". 
certamente, como em Botticelli, um elemento dionisíaco, no caso, uma atuação desfreada, descontrolada entusiasta, que o artista associa ao caminho que leva a morte. Já na parte superior direita da gravura, esta cena é contrastada pela iconografia de uma porta estreita com uma cruz vazia na sua parte superior. Por essa porta passam ou tinham passado três pessoas carregando, individualmente, uma cruz, subindo um caminho estreito e íngreme. Todos esses detalhes são mais uma vez elementos clássicos da iconografia dos dois caminhos, citados, obviamente, de forma consciente. Aqui se articula um aspecto apolíneo, sereno, a capacidade de controlar as paixões furiosas. Seguindo Aby M. Warburg, vemos aqui clássicas fórmulas de páthos oriundo, quanto às ninfas, até da Antiguidade pré-cristã; quanto os portais, do texto bíblico, ou seja, da Antiguidade tardia do cristianismo primitivo. Além disso, representa a gravura uma síntese entre dois motivos distintos no texto bíblico: o motivo de tomar a sua própria cruz de Mateus 10.37-38 e o motivo da porta estreita e da porta larga de Mateus 7.13-14), ${ }^{20}$ algo que as imagens podem fazer, mas não o texto.

Na segunda obra aqui investigada, Samuel Wesley faz um uso ainda mais amplo de imagens. Obviamente, ele está confortável com o emprego da cultura visual, conhece diferentes narrativas visuais e emprega elas, aceitando, inclusivo o rico repertório da sua época. A integração da linguagem dos livros com emblemas na capa sinaliza um certo perfil de leitor[as] que ativa - e conscientemente procura o significado do texto -, inclusive em conversa com imagens, usando seu saber cultural para encontrar e seguir, afinal, seu caminho.

\section{Considerações finais}

Samuel Wesley é um autor religioso que atuava, principalmente, na época conhecida como a restauração inglesa. Ele deixou na sua juventude o puritanismo e abraçou os novos tempos como sacerdote anglicano e monarquista.

Quanto a escolha dos seus colaboradores, os gravuristas William Faithorne e John Sturt, ele demonstrou uma busca por excelência. Mesmo que Faithorne assumiu a sua participação na Vida de Cristo (1693) ao final da sua carreira, e John Sturt, na Vida de Cristo e as Histórias do Novo e do Antigo Testamento, em um momento que a sua estrela ainda estava em ascensão,

20 Eventualmente, se faz também referência ao motivo da prostituta segundo Apocalipse 17.1 e 19.2, o que seria um motivo comum nas gravuras dos dois caminhos. Esta última referência depende da interpretação da postura corporal, dos gestos e dos atributos da figura feminina no centro-esquerda. Caso que ela segura uma fronde, representaria uma serva ou escrava. Já pisar com o seu pé esquerdo a uma cabeça de uma pessoa no chão, sinaliza o ato de governança. 
dando continuidade à sua colaboração com Francis Bragge, os dois eram (já) conhecidos e apreciados. A colaboração com John Sturt coloca a iniciativa iconográfica de Samuel Wesley, além disso, numa linha de outros fornecedores de textos devocionais, inclusive, os dois representantes mais "icônicos" de todos os tempos, o católico Hugo Herman e o puritano John Bunyan. Samuel Wesley fez parte dessa mesma cultura que empregou narrativas visuais e textuais juntas para anunciar o evangelho e guiar as pessoas.

Nessa cultura iconográfica, o emprego de gravuras segue diversos objetivos, usando várias formas. A nossa escolha foi, obviamente, reduzida demais para fazer afirmações genéricas. Por causa disso, escolhemos duas capas ou gravuras de título cuja iconografia sempre "encaminha" o[a] leitor[a], articula um primeiro acento, enfim, prepara a leitura. Nos dois casos, identificamos uma linguagem visual soteriológica. Além disso, sinaliza já esse conjunto pequeno de gravuras estudado, por meio do seu uso de linguagens visuais, seus estilos diversos e apelos diferenciadas, uma significativa variedade. Um dominador comum entre essas imagens é que suas linguagens - estrutura de um emblema, motivo do Cristo Salvador Mundi e integração de motivos os elementos da linguagem visual da Antiguidade - foram todas criadas na Renascença na Itália e não, por exemplo, durante o Barroco ou no Rococó. Mas, pela quantidade dos exemplos, isso pode servir somente como uma primeira impressão. De qualquer forma, sinalizam a variedade e as origens, que os dois artistas são profundos conhecedores da cultura visual da sua época, das suas técnicas e possibilidades e que todo isso acabou indo para as obras editadas por Samuel Wesley. Dificilmente, Samuel Wesley não sabia disso; supomos que ele empregou isso como um dos elementos de anunciar o evangelho e que esperava que seus leitores e suas leituras teriam, no mínimo, uma certa competência de ler essas linguagens visuais, diversas e ricas, inclusive, de pessoas com uma escolaridade mais humilde. ${ }^{21}$

Em qualidade de uma hipótese, já que para uma conclusão ainda falta um estudo mais ampla, registramos também duas linguagens visuais que articularam paixões e afetos como parte da condição humana e horizonte para o homo religioso. Com certeza podemos dizer que Samuel Wesley, na época, não teria sido sozinho nessa ênfase. A ênfase no afeto ou na emoção na religião, era o programa iconográfico da reforma católica desde 1580 e eram ambos elementos-chave na sua expressão artística mais pura, o Barroco. Mas Wesley não dependia disso. Esses elementos podem ser também encontrados em autores como Bunyan - o que faz da ilustração posterior da sua obra

21 Identificamos também em John Wesley, um dos seus filhos, uma compreensão parecida, quanto à competência emblemática em pessoas mais humildes (RENDERS, 2014, p. 83-95). 
por Stuart um ato consequente. Nos três motivos estudados, a "Natalidade", "O assassinato das crianças" e "Os dois caminhos", encontramos linguagens afetivas, de paixões até furiosas e dramáticas, com outras palavras, o que Aby M. Warburg em seus estudos da arte Renascentista classificou como "Fórmulas de patos", com as suas dimensões dionisíacas e apolíneas. No caso dos primeiros motivos, cada um representava uma dessas paixões, no caso do último motivo, o aspecto dionisíaco domina, mas, o aspecto apolíneo tem a sua expressão paralela na indicação do caminho estreito. Isso se distancia, claramente, de uma leitura meramente racionalista do texto bíblico.

Nesta direção aponta também a sua linguagem que Samuel Wesley adota nestas duas obras, a linguagem poética. Ela não era assunto da sua pesquisa, mas, no sentido de um horizonte, é importante ressaltar que as narrativas visuais são paralelas a narrativas poéticas e ambas aparecem como auxílios interpretativos do texto bíblico. Isso, no mínimo, fortalece a tese que as imagens não são meras ilustrações do texto, mas uma de duas linguagens adicionais. Quanto a essa duplicidade de linguagens religiosas adicionais, chama, finalmente, a atenção que Samuel em nenhum instante, justifica, defende o problematiza o uso das gravuras. Diferentemente, recebe a parte poética uma atenção especial, especialmente por documentar a sua explicita aprovação por celebridades e colegas poetas da época e uma introdução na "poética heroica", escrita pelo próprio Samuel Wesley. Parece que enquanto se sentia a necessidade de uma explicação por parte do seu autor e da apreciação promocional das suas poesias, as imagens ocupam seu lugar com a maior tranquilidade e naturalidade.

\section{Referências bibliográficas}

\section{Fontes primárias ${ }^{22}$}

WESLEY, Samuel. Maggots, or poems on several subjects never before handled by a scholar. London: for John Dunton, 1685. 188p.

WESLEY, Samuel. The live of our blessed Lord \& Savior Jesus Christ: a heroic poem dedicated to their most sacred Majesty. With sixty copperplates [de W. Fairborn]. London: printed for Charles Harper and M. Motte. 1693 382p. [British Library: Disponível em: < http://acess. bl.uk/item/viewer/ark:/81055/vdc_0000002A9F0 >]

2. ed. WESLEY, Samuel. The Life of Our Blessed Lord and Savior Jesus Christ. An Heroic Poem Dedicated to Her Most Sacred Majesty: in Ten Books. London: Printed for Charles Harper at the Flower-de-Luce over against St. Dunstan ${ }^{5}$ S Church, and are to be sold by him, and Roger

22 Em ordem cronológica. Unimos também as diferentes edições das mesmas obras. 
Clavel at the Peacock against Fetter-Lane, both in Fleetstreet, 1697.

[COKE, Thomas. The life of Christ, a poem: originally written by the Rev. Samuel Wesley, vicar of Epworth in Lincolnshire, father of the late Rev. and venerable John Wesley: corrected, abridged, enlarge by much original matter, and preented to the public in an almost entire new dress. 2 volumes. London: impresso para Thomas Coke, 1809.]

Fac-símile: WESLEY, Samuel. The live of our blessed Lord \& Savior Jesus Christ: a heroic poem dedicated to their most sacred Majesty. With sixty copperplates. Charleston, SC: British Library, Historical Print Editions, 2011. 528p.

WESLEY, Samuel. Elegies on the Queen and Archbishop. London: B. Motte for C. Harper, 1695.

WESLEY, Samuel. A Sermon concerning reformation of manners preach'd at St. Jame's

Church. Westminster Feb. 13, and afterwards at St. Brides, to one of the religious societies.

London: Charles Harper, 1698.

WESLEY, Samuel. An Epistle to a Friend Concerning Poetry. London: Charles Harper, 1700a.

WESLEY, Samuel. The Pious Communicant rightly prepar'd, or, A discourse concerning the Blessed Sacrament: wherin the nature of it is described... With prayers and hymns ...To which is added, a short discourse of baptism. London: Charles Harper, $1700 \mathrm{~b}$. Disponível em: < https://ia803100.us.archive.org/17/items/piouscommunicant00wesl/ piouscommunicant00wesl.pdf >. Acesso em: 24 abr. 2020.

2. ed. WESLEY, Samuel. The holy communicant rightly prepar'd, or, A discourse concerning the Blessed Sacrament: wherein the nature of it is describ'd, our obligation to frequent communion enforc'd, and directions given for due preparation for it, behaviour at, and after it, and profiting by it: with prayers and hymns, suited to the several parts of that holy office: to which is added, a discourse on baptism. London: Printed for G. Davis, 1716.

Fac-símile: WESLEY, Samuel. The holy communicant rightly prepar'd, or, A discourse concerning the Blessed Sacrament: wherein the nature of it is describ'd, our obligation to frequent communion enforc'd, and directions given for due preparation for it, behaviour at, and after it, and profiting by it: with prayers and hymns, suited to the several parts of that holy office: to which is added, a discourse on baptism.Gale Ecco, Print Editions, 2018.

WESLEY, Samuel. The history of the New Testament attempted in verse and adorn'd with one hundred \& fifty two sculptures. The cuts done by John Sturt. London: For Charles Harper, 1701.

2. ed. WESLEY, Samuel. The history of the New Testament attempted in verse and adorn'd with one bundred \& fifty two sculptures. The cuts done by John Sturt. London: For Charles Harper, 1715.

3. ed. WESLEY, Samuel. The History of the Old and New Testament attempted in verse: and adorn'd with three hundred and thirty sculptures. London: Printed for C. Harper, 1716 [como volume 1 da edição em 3 voumes].

4. ed. WESLEY, Samuel. The history of the New Testament attempted in verse and adorn'd with one bundred \& fifty two sculptures. The cuts done by John Sturt. London: For Thomas Ward, 1717a. 332p.

Fac-símile: WESLEY, Samuel. The history of the New Testament attempted in verse and adorn'd with one bundred \& fifty two sculptures. The cuts done by John Sturt. London: For Thomas Ward. Forgotten Books, 2019. 
WESLEY, Samuel. An Account of the Religious Society begun in Epworth, in the Isle of Axholm Lincolnshire, Feb: 1, An: Dom: 1701-2.

WESLEY, Samuel. A Letter from a country divine to his friend in London: concerning the education of the dissenters, in their private academies, in severed parts of this nation: humbly offer'd to the consideration of the Grand Committee of Parliament for Religion, now sitting. London: Printed for R. Clavel at the Pecock in the St. Paul's Church-Yard, 1703.

WESLEY, Samuel. A Defence of a Letter Concerning the Education of Dissenters in Their Private Academies: With a more full and satisfactory account of the fame, and of their morals and Behaviour towards the Church of England: Being an Answer to the Defence of the Dissenters Education. Published anonymously and without consent, 1704a.

WESLEY, Samuel. The History of the Old Testament attempted in verse: and adorn'd with three hundred and thirty sculptures. 2 volumes, London: Printed for C. Harper, 1704b.

2. ed. WESLEY, Samuel. The History of the Old Testament attempted in verse: and adorn'd with three hundred and thirty sculptures. London: Printed for John Hooke, 1715.

3. ed. WESLEY, Samuel. The history of the Old and New Testament: attempted in verse and adorn'd with three hundred \& thirty sculptures. The cuts done by John Sturt, 1716. [volumes 2 e 3 da edição em 3 volumes].

Fac-símile: WESLEY, Samuel. The history of the Old and New Testament. attempted in verse and adorn'd with three hundred \& thirty sculptures. The cuts done by John Sturt. Forgotten Books, 2019.

WESLEY, Samuel. Marlborough; or, The fate of Europe: a poem. Dedicated to the Right Honourable Master Godolphin. London: Charles Harper, 1705.

WESLEY, Samuel. A reply to Mr. Palmer's Vindication of the learning, loyalty, morals, and most Christian behaviour of the Dissenters towards the Church of England. London: Robert Clavel, 1707.

WESLEY, Samuel. An bymn on peace: to the Prince of Peace. London: J. Leake, 1713.

WESLEY, Samuel. The battle of the sexes - a poem. London: Printed for J. Brotherton, 1724.

WESLEY, Samuel; STEVENS, Nicholas. Two letters from a deist to his friend: concerning the truth and propagation of deism, in opposition to Christianity, with remarks. [Dublin]: London printed: S. Powell, 1730.

[WESLEY, Samuel]. Advice to a young clergyman: in a letter to him, concerning: I. His Intention. II. Converse and demeanor. III. Reading Prayers. IV. Studies. V. Preaching and catechising. VI. Administering the sacrament. Lastly, discipline/by a divine of the Church of England. London: C. Rivington, 1735. (November, 1730)

\section{Edicões póstumas}

WESLEY, Samuel. Dissertationes in Librum Jobi. Londini: Typis Gulielmi Bowyer, 1736.

WESLEY, Samuel. Poems on several ocasions. London: Printed by E Say. 1736.

Fontes secundárias

ANTHOLOGIA do Natal. São Paulo, SP: Imprensa Metodista, [19_?]. 70 p.

BARBOSA, Walker da Costa. Zambo ou a procissão dos aflitos: Poema cíclico. São Bernardo do Campo, SP: Imprensa Metodista, 1972. 
BOOK OF COMMON PRAYER. Com gravuras de John Sturt. Oxford: 1731

BRAGGE, Francis. The passion of our Saviour: a pindarick ode on the suffering God, in imitation of Rapins Christus patiens. Gravuras de John Sturt. [s.l.]: 1694.

BUNYAN, Joao. O peregrino: ou a viagem do cristão à cidade celestial. 15. ed. São Paulo, SP: Imprensa Metodista, 1981. 209 p., il.

BUNYAN, John. Pilgrim's Progress. Com gravuras de John Sturt, 1728.

CHAMBERLIN, William J. Catalogue of English Bible translations: A classified bibliography of versions and editions including books, parts, and Old and New Testament Apocrypha and apocryphal books. New York: Greenwood Press, 1991 [Bibliographies and Indexes in Religious Studies, vol. 21] 150p.

DAICHES, David (ed.). A Critical History of English Literature: The Restoration to the present day, vol. 2. London: Martin Secker and Warburg ltd,1996.

DUARTE, Jose Bezerra. Inspirações do acaso. São Paulo: Imprensa Metodista, 1969.

FAGAN, Louis Alexander. Faithorne, William (1616-1691). In: STEPHEN,

Leslie (ed.). Dictionary of National Biography. Vol. 18. London: Smith, Elder \& Co, 1886, p. 154-155.

FAGAN, Louis Alexander. Faithorne, William (1656-1701?). In: STEPHEN, Leslie (ed.). Dictionary of National Biography. Vol. 18. London: Smith, Elder \& Co, 1886, p. 155-156.

GIÓIA JÚNIOR. Poemas em feitio de oração. São Paulo: Imprensa Metodista, 1974.

GONCALVES, Antonio de Campos. Outrora e hoje. São Paulo: Imprensa Metodista, s.d. GONCALVES, Antonio de Campos. Yolanda. Rio de Janeiro: s.n., 1945. 74 p.

GRIFFITH, Acton Frederick. Bibliotheca Anglo-poetica, or, a descriptive catalogue of a rare and rich collection of early English poetry. London: Impresso para Thomas Davidson, 1815.

HERMAN, Hugo. Pia desideria: or, divine addresses: in three books. Tradução do latim: Edmund Arwaker. 47 gravuras de John Sturt. 3. ed. revisada. London: impresso para Henry Bonwick, 1702.

NUNES, Dario. Gotas de orvalho: Poesias. São Paulo: Imprensa Metodista, 1971.

O’DONOGHUE, Freeman Marius. Sturt, John. In: STEPHEN, Leslie (ed.). Dictionary of National Biography. Vol. 55. London: Smith, Elder \& Co. 1900, p. 138-139.

OLIVEIRA, Valdomiro Pires de. Aquarelando: um novo tempo começa pela poesia. São Bernardo do Campo, SP: Imprensa Metodista; São Paulo: CEBEP, 1986. 78 p., il.

PINHEIRO, Josias de Paiva. Alma cristã: Poesia. São Paulo: Imprensa Metodista, 1972.

PINHEIRO, Josias de Paiva. Faíscas: trovas. São Bernardo do Campo, SP: Imprensa Metodista, s.d.p. 58 p.

RENDERS, Helmut. Gravuras nas obras de John Wesley: ilustrações, ornamentos, print flowers e emblemas. Estudos de Religião, São Bernardo do Campo, v. 33, n. 1, p. 103-124, jan./ abr., 2019.

RENDERS, Helmut. Um emblema social metodista: a águia e o coração com chamas, ou a misericórdia divina que permite recomeços. Caminhando, São Bernardo do Campo, v. 19, n. 1, p. 83-95, jan./jun., 2014. 
RICHETTI, Joh (ed.). The Cambridge History of English Literature, 1660-1780. The New Cambridge History of English Literature. London: Cambridge University Press, 2005. S.N. Faithorn, William [Verbete]. NAGLER, Georg Kasper (ed.). In: Neues allgemeines Kunstler-Lexicon: oder Nachrichten von dem Leben und dem Werke der Bildhauer, Baumeister, Kupferstecher, Formstecher, Litographen, Zeichner, Medailleure, Elfenbeinarbeiter, etc. vol. 3, München: Verlag von E.A. Fleischmann, 1836, p. 233-234; S.N. Bibliotheca heberiana. Catalogue of the library of the late Richard Heber. Parte the fourth, removed from his house at Pimlico. London: 1834.

S.N. Samuel Wesley, the elder [verbete]. In: WATSON, George; WILLISON, Ian R.; PICKLES, J.D. (eds.). The New Cambridge Bibliography of English Literature. Vol. 2 [1660-1800]. London: Cambridge University Press, 1971. col. 487

SHERBURNE, George e BOND, Donald F. (ed.). The Literary History of England. Vol. 3 [The Restoration and Eighteenth century]. London: Rootledge, 1967.

TORPY, Arthur Alan. The prevenient piety of Samuel Wesley, Sr. 2009. (Coletânea: Pietist and Wesleyan Studies, vol. 30).

TORPY, Arthur Alan. The prevenient piety of Samuel Wesley, Sr. Tese (Doutorado). P.P.G. Religious Sciences. Baylor University, Waco, Texas, 2006. Disponível em: Disponível em: < https://baylor-ir.tdl.org/bitstream/handle/2104/4826/Art_Torpy_phd. pdf? sequence $=1 \&$ isAllowed $=\mathrm{y}>$. Acesso em: 25 abr. 2020.

VIANA, Antonio. Rosas e espinhos. São Paulo: Imprensa Metodista, 1940.

Submetido em: 1-6-2020

Aceito em: 24-9-2020 